\title{
O ENADE COMO INDUTOR DA QUALIDADE DA EDUCAÇÃO SUPERIOR
}

CLAUDIA MAFFINI GRIBOSKI

\section{RESUMO}

O foco principal deste trabalho está na implementação do Sistema Nacional de Avaliação da Educação Superior, com o objetivo de avaliar a qualidade dos cursos de graduação oferecidos pelas Instituições de Educação Superior. Ao discutir a democratização da educação superior, ocorrida por meio da expansão do acesso, acompanham-se os avanços das políticas de avaliação implementadas na última década. De forma especial, analisam-se o Exame Nacional de Desempenho dos Estudantes e as respectivas alterações metodológicas desde a sua implementação, em 2004, a fim de identificar suas contribuições para a melhoria da qualidade da educação superior. Combinando os resultados do exame com os indicadores de qualidade e com os resultados alcançados na avaliação externa por meio das visitas in loco, reflete-se sobre a forma de avaliar a qualidade de cursos de graduação e das instituições de educação superior.

PALAVRAS-CHAVE AVALIAÇÃO DA EDUCAÇÃO • ENSINO SUPERIOR • AVALIAÇÃO INSTITUCIONAL・ QUALIDADE DE ENSINO. 


\section{RESUMEN}

El foco principal de este trabajo está en la implementación del Sistema Nacional de Evaluación de la Educación Superior con el objetivo de evaluar la calidad de los cursos de graduación ofrecidos por las Instituciones de Educación Superior. Al discutir la democratización de la Educación Superior, por medio de la ampliación del ingreso, se acompañan los avances de las políticas de evaluación implementadas en la última década. De forma especial, se analiza el Examen Nacional de Desempeño de los Estudiantes y las respectivas alteraciones metodológicas desde su implementación en 2004, con el fin de identificar las contribuciones para la mejora de la calidad de la educación superior. Combinando los resultados del Enade con los indicadores de calidad con los resultados alcanzados en la evaluación externa por medio de las visitas in loco, se realiza una reflexión sobre la forma de evaluar la calidad de cursos de graduación y de las instituciones de educación superior.

PALABRAS CLAVE EVALUACIÓN DE LA EDUCACIÓN •

ENSEÑANZA SUPERIOR • EVALUACIÓN INSTITUCIONAL・ CALIDAD DE LA ENSEÑANZA.

\section{ABSTRACT}

The main focus of this article is on the implementation of the National System of Higher Education Assessment with the aim of evaluating the quality of undergraduate courses offered by Institutions of Higher Education. In discussing the democratization of higher education, by expanding access to it, the article follows the progress of evaluation policies implemented during the last decade. In particular, it analyzes the National Examination of Student Performance and the methodological changes it underwent since its implementation in 2004, in order to identify their contributions to improve the quality of higher education. Combining the results of the exame with the quality indicators with the results of the external evaluation through on site visits, it puts forward a reflection on how to assess the quality of undergraduate courses and of Institutions of higher education.

KEYWORDS EDUCATIONAL EVALUATION • HIGHER EDUCATION

- INSTITUTION EVALUATION • TEACHING QUALITY. 


\section{INTRODUÇÃO}

10 Sinaes tem por finalidades a melhoria da qualidade da educação superior, a orientação da expansão da sua oferta, o aumento permanente da sua eficácia institucional, a ampliação da sua efetividade acadêmica e social e, especialmente, a promoção do aprofundamento dos compromissos responsabilidades sociais das instituições de educação superior, por meio da valorização de sua missão pública, da promoção dos valores democráticos, do respeito à diferença e à diversidade, da afirmação da autonomia e da identidade institucional ( $§ 10$ Art. 1ำ da Lei n. 10.861/2004)
O Sistema Nacional de Avaliação da Educação Superior (Sinaes), ${ }^{1}$ instituído em 14 de abril de 2004, por meio da Lei n. 10.861, apresenta, dentre seus objetivos, a permanente busca pela melhoria da qualidade da educação superior, pela sua expansão e pelo acompanhamento da oferta dos cursos de graduação do sistema federal.

Com a implementação do Sinaes, o Exame Nacional de Desempenho dos Estudantes (Enade) passou a substituir o Exame Nacional de Cursos (ENC), conhecido como Provão, criado pela Lei n. 9.131/1995 e aplicado, no período de 1996 a 2003, apenas aos estudantes concluintes e com o objetivo de avaliar os respectivos cursos de graduação. A partir da implantação do Sinaes, em 2004, o objetivo do Enade é ampliado e passa a integrar a avaliação de cursos e instituições e a expressar o desenvolvimento da aprendizagem dos estudantes ingressantes e concluintes dos cursos de graduação, em consonância com as Diretrizes Curriculares Nacionais (DCN) para os cursos ofertados.

Tendo em consideração que cresce vertiginosamente o número de novas instituições e de novos cursos de graduação a 
cada ano, as mudanças ocorridas nos processos de avaliação têm tido, por parte do Estado, a intenção de garantir a qualidade da educação superior ofertada no país, principalmente em tempos de expansão do acesso. A partir do ano de 1996, quando ocorreu a primeira aplicação do Provão ${ }^{2}$ aos estudantes concluintes dos cursos de graduação, houve um crescimento no número de vagas e de Instituições de Educação Superior, de 894 instituições e 1.759.703 matrículas, em 1995, para 2.314 instituições e 5.954.021 matrículas, em 2009, conforme dados do Censo da Educação Superior, realizado pelo Instituto Nacional de Estudos e Pesquisas Educacionais Anísio Teixeira (BRASIL, 2011).

Diante dessa situação, é premente a necessidade de acompanhar a evolução da qualidade da educação superior, a partir da análise da ampliação da participação e das políticas de avaliação utilizadas para subsidiar o processo de regulação e supervisão realizado pelo Ministério da Educação.

É a partir dessa perspectiva que o presente artigo busca discutir a democratização da educação superior e os avanços das políticas de avaliação, com foco principalmente no Enade e no uso dos seus resultados na Gestão da Educação.

Para tanto, apresentam-se na parte inicial do artigo as características da educação brasileira e sua evolução, com vistas à ampliação da sua oferta e à crescente participação na avaliação. E, ainda, discutem-se os instrumentos e indicadores criados com a finalidade de regular, supervisionar e manter a qualidade $^{3}$ da educação superior.

Na segunda parte, destaca-se o Enade como um dos elementos imprescindíveis para a avaliação da educação superior, pela forma de obtenção de dados válidos na organização e reorganização dos currículos e pela indução da prática formativa esperada dos cursos de graduação. Nesse sentido, afirma-se que os resultados positivos do uso da avaliação dependem de uma ação política do Estado, articulada com as demais instâncias da sociedade para a prestação de contas e promoção da qualidade. Uma verdadeira engenharia de elaboração dos exames é esclarecida na sequência do texto, com a apresentação da metodologia de organização dos instrumentos de medição, que possui a finalidade de trazer maior confiança às Instituições de Educação Superior (IES), aos docentes dos cursos, aos
2 Em 1995, foi instituída a Lei n. 9.131, regulamentada em 1996 através do Decreto n. 2026, que estabeleceu procedimentos para o processo de avaliação dos cursos e instituições de ensino superior. Um dos procedimentos de avaliação era o Exame Nacional de Cursos (ENC), que vigorou de 1996 a 2003. O Provão foi considerado um instrumento indicador de eficácia dos cursos e das IES, embora utilizando somente os resultados do desempenho dos alunos.

3 O Decreto n. 5.773/2006 dispõe sobre o exercício das funções de regulação, supervisão e avaliação das Instituições de Educação Superior, dos cursos superiores de graduação e dos cursos sequenciais no sistema federal de ensino. $\S 1$ 10 A regulação será realizada por meio de atos administrativos autorizativos do funcionamento de Instituições de Educação Superior e de cursos de graduação e sequenciais. § 2ำ A supervisão será realizada a fim de zelar pela conformidade da oferta de educação superior no sistema federal de ensino com a legislação aplicável. § 3으 A avaliação realizada pelo Sistema Nacional de Avaliação da Educação Superior -

Sinaes - constituirá referencial básico para os processos de regulação e supervisão da educação superior, a fim de promover a melhoria de sua qualidade. 
4 Art. 33. O ciclo avaliativo compreende a realização periódica da avaliação de instituições e cursos superiores, tendo como referência as avaliações trienais de desempenho de estudantes, as quais subsidiam, respectivamente. os atos de recredenciamento e de renovação de reconhecimento (NR) (Portaria Normativa $n$ 40/2007, republicada em 29 de dezembro de 2010) estudantes e à sociedade, que se mobiliza para obtenção de informações confiáveis da avaliação.

Ampliando o debate, apresenta-se, na terceira parte, o papel dos indicadores de qualidade no contexto da avaliação da educação superior na formulação de bases e referenciais sólidos que subsidiem o processo e, mais uma vez, tem-se em conta que o Enade é o ponto de partida e também o ponto de chegada da avaliação. Tudo se inicia com a avaliação do estudante (Enade), que possibilita o cálculo dos insumos para compor o conceito preliminar de curso (CPC). Com a média dos CPCs, realiza-se o cálculo do indicador de qualidade da instituição (IGC) e, em seguida, realizam-se as avaliações in loco, que podem ou não confirmar os resultados alcançados na avaliação e dar uma visão plena do padrão de qualidade da oferta da educação superior. Trata-se de um ciclo avaliativo ${ }^{4}$ que permite ao avaliador e ao avaliado traçarem rumos, metas e inovação na busca da qualidade.

Na quarta parte do texto, discute-se a participação da comunidade acadêmica nas políticas de avaliação da educação superior e nos processos de construção dos instrumentos de avaliação.

Nas considerações finais, alerta-se para o fato de o Enade ser um elemento indutor da qualidade da educação superior, a partir das contribuições que os resultados das avaliações podem trazem para o aprimoramento do curso e para a própria formação dos estudantes de graduação.

\section{CARACTERÍSTICAS DA EDUCAÇÃO SUPERIOR DO BRASIL}

Diante da crescente expansão da educação superior, conforme dados do Censo da Educação Superior/Inep/2009 (Tabela 1), o sistema federal de educação superior registra 28.671 cursos de graduação, sendo que, destes, 3.952 são cursos criados no último ano (13,7\%). Do total de cursos de graduação, 69,9\% encontram-se na esfera privada, o que representa a manutenção da trajetória histórica do acesso à educação superior por meio das instituições particulares. 
TABELA 1 - Estatísticas básicas da educação superior

\begin{tabular}{|c|c|c|c|c|c|c|}
\hline \multirow{3}{*}{$\begin{array}{c}\text { CURSOS DE } \\
\text { GRADUAÇÃO }\end{array}$} & \multicolumn{6}{|c|}{ CATEGORIA ADMINISTRATIVA } \\
\hline & \multirow{2}{*}{$\begin{array}{l}\text { TOTAL } \\
\text { GERAL }\end{array}$} & \multicolumn{4}{|c|}{ PÚBLICA } & \multirow{2}{*}{ PRIVADA } \\
\hline & & Total & Federal & Estadual & Municipal & \\
\hline \multicolumn{7}{|c|}{ ESTATÍSTICAS BÁSICAS } \\
\hline Instituições & 2.314 & 245 & 94 & 84 & 67 & 2.069 \\
\hline Cursos & 28.671 & 8.628 & 4.647 & 3.245 & 736 & 20.043 \\
\hline $\begin{array}{l}\text { Ingressos } \\
\text { (todas as } \\
\text { formas de } \\
\text { ingresso) }\end{array}$ & 2.065 .082 & 422.329 & 253.642 & 133.425 & 35.253 & 1.642 .762 \\
\hline Matrículas & 5.954 .021 & 1.523 .864 & 839.397 & 566.204 & 118.263 & 4.430 .157 \\
\hline Concluintes & 959.197 & 206.877 & 93.510 & 93.049 & 20.318 & 752.320 \\
\hline $\begin{array}{l}\text { Funções } \\
\text { docentes em } \\
\text { exercício }\end{array}$ & 340.817 & 122.977 & 72.228 & 43.145 & 7.604 & 217.840 \\
\hline $\begin{array}{l}\text { Matrículas } \\
\text { de Pós- } \\
\text { graduação }\end{array}$ & 161.068 & 133.069 & 85.787 & 46.413 & 869 & 27.959 \\
\hline \multicolumn{7}{|c|}{ INDICADORES - RAZÃO } \\
\hline $\begin{array}{l}\text { Cursos/ } \\
\text { Instituição }\end{array}$ & 12,39 & 35,22 & 49,44 & 38,63 & 10,99 & 9,69 \\
\hline $\begin{array}{l}\text { Matrículas*/ } \\
\text { funções } \\
\text { docentes em } \\
\text { exercício }\end{array}$ & 17,94 & 13,47 & 12,81 & 14,20 & 15,67 & 20,47 \\
\hline
\end{tabular}

* Inclui matrículas de Graduação e de Pós-Graduação.

É notório o aumento da participação de estudantes no nível superior. Em 2009, são 5.954.021 estudantes. Entretanto, enquanto política de Estado, o que se espera é um crescimento do acesso à educação superior na rede pública de ensino, pois atualmente $74,4 \%$ das matrículas estão concentradas na rede privada. Isso evidencia ainda a dificuldade dos estudantes na conclusão dos estudos, muitas vezes devido às altas mensalidades praticadas pelas instituições, ou mesmo à dificuldade de conciliar as atividades acadêmicas e profissionais.

Dos 959.197 estudantes que concluíram os estudos em 2009, 752.320 estavam em instituições privadas e 206.877 em instituições públicas. Se compararmos a matrícula total de 
5 Texto do PNE 2011-2020: Meta 12 - Elevar a taxa bruta de matrícula na educação Superior para $50 \%$ e a taxa líquida para 33\% da população de 18 a 24 anos, assegurando a qualidade da oferta; amplia a atuação de mestres e doutores nas instituições de ensino superior para, no mínimo, 75\% do corpo docente em efetivo exercício. Desse grupo, pelo menos 35\% devem ser doutores; expandir gradualmente o número de matrículas na pós-graduação stricto sensu, a fim de formar anualmente $60 \mathrm{mil}$ mestres e 25 mil doutores.
5.954.021 estudantes à dos concluintes, apenas $16,11 \%$ são os que conseguem concluir os cursos. Atualmente, tem-se 4.430 .157 estudantes matriculados nas instituições privadas, e 16,9\% são os concluintes. Já na esfera pública, embora sejam somente 206.877 estudantes concluintes, o índice em relação às 1.523 .864 matrículas atuais é de 13,5\%, portanto, pode-se inferir que há um menor número de evasão ou abandono na rede pública.

Segundo Oliveira (2002), após 1968, ocorreu uma expansão do sistema privado de ensino superior, o que criou inúmeras faculdades isoladas na periferia das grandes metrópoles e em algumas cidades do interior dos estados mais desenvolvidos. Coube ao sistema privado atender à demanda por educação superior de setores estudantis excluídos da forte seletividade das universidades federais. Devido à expansão das instituições particulares, ocorreu a ampliação das matrículas, de forma elitizada, o que corroborou a crítica da sociedade quanto ao não comprometimento do Estado com a expansão de instituições públicas que atendessem às demandas regionais de acesso à educação superior.

Para Dias Sobrinho (2009), tratar da universidade e da democracia, hoje, obriga a refletir sobre a globalização, pois os problemas da universidade não dizem respeito somente a ela mesma, mas são problemas de toda a sociedade. Há uma grande expectativa dos grupos sociais pela evolução da dinâmica de atendimento às demandas sociais, e a educação superior sofre pressões para romper com a ideia tradicional de organização e para crescer, ocupando os espaços que a rede pública não consegue alcançar.

Esse movimento de crítica à necessária expansão da rede pública tomou força na reforma da educação superior, nas metas do Plano Nacional de Educação (PNE) para o período de 2001 a 2010 e passou a pressionar o governo por políticas de ampliação de vagas nas Universidades e Institutos Federais de Educação Superior. A meta 6 do PNE (2001-2010) propõe institucionalizar um amplo e diversificado sistema de avaliação interna e externa, que englobe os setores público e privado e promova a melhoria da qualidade do ensino, da pesquisa, da extensão e da gestão acadêmica.

Não é diferente no PNE (2011-2020), ${ }^{5}$ no qual a política educacional para a educação superior consiste na busca contínua 
de expansão por meio da diversificação da oferta, aumento das matrículas e racionalização dos recursos nas instituições públicas. Oferece, ainda, subsídios para aumentar a articulação dos currículos dos cursos de graduação com as necessidades do mundo do trabalho e para fortalecer o sistema de avaliação, de forma que oriente os aspectos regulatórios e a decisão da gestão.

Mesmo tendo o Brasil expressado o princípio da educação como um direito na Constituição Federal de 1988, o movimento dessa oferta pelo viés público e privado, por vezes, tem se constituído como fonte fácil de obtenção de lucros. Amaral (2009) contribui para essa reflexão sobre a forma de organização da educação, entendida como um serviço prestado à população e distanciada, portanto, de um bem público de direito a ser garantido pelo Estado.

As alterações em curso não são apenas ajustamentos estruturais. Há mudanças de ideologia e de valores, e mudanças significativas no relacionamento entre as instituições de ensino superior e o Estado. A educação é hoje considerada mais como um ingrediente indispensável para a concorrência econômica e menos como um direito social, e está se tornando cada vez mais um serviço. (AMARAL, 2009, p. 15)

De fato, se a concepção mercadológica, que permeia a expansão da educação superior, não for acompanhada por processos avaliativos de qualidade dissociados da prática punitiva e restritiva tradicional que tem motivado a resistência das instituições, pouco se avançará na lógica do direito à educação, do respeito à identidade institucional e da construção da cidadania. É somente por meio da reflexão, confiança e participação que haverá sujeitos envolvidos no processo de reforma da educação superior e de tomada de decisão sobre as políticas avaliativas.

\footnotetext{
Um dos principais objetivos que sempre acompanhou a expansão da educação em todo o mundo, é a função democratizadora da Universidade. Na época moderna, a conquista pelo direito à educação passou a ser considerada como parte da ampliação do próprio conceito de cidadania, junto com o direito ao voto e a condições mínimas de assistência social, salário e condições adequadas de trabalho. (SCHWARTZMAN, 2008, p. 79)
} 
Conforme Schwartzman (2008), o acesso às informações é uma das principais premissas da democratização, ou seja, quanto mais informada estiver a população, mais crítica será a sua participação e maior contribuição poderá dar à construção da sociedade. O acompanhamento das informações referentes ao acesso à educação superior, bem como às atualizações das normas e aos procedimentos adotados para a implementação do Sinaes é, pois, de fundamental importância para o desenvolvimento da cidadania e para a noção de pertencimento dos indivíduos com relação à sociedade.

Portanto, a definição de uma nova dinâmica na organização da educação superior depende da relação que se estabelece entre a Universidade e a Sociedade. E este é o grande desafio, o de construir uma proposta de universidade inclusiva, fundada nos princípios da ética e que possibilite repensar os valores da formação e a importância do conhecimento como bem público.

Isso requer uma ampla participação de estudantes, professores e pesquisadores na definição de prioridades sociais e na produção e socialização do conhecimento rigoroso e pertinente. Em outras palavras é preciso instaurar uma ética de responsabilidade social, que vincule os atores acadêmicos e os agentes da sociedade civil organizada às agendas públicas realmente voltadas ao atendimento das demandas das populações, e não meramente à validação e à legitimação dos projetos mercantilistas da globalização neoliberal. (DIAS SOBRINHO, 2009)

As políticas de avaliação da educação superior devem ser pensadas a partir desse novo paradigma ético e político da sociedade atual, sem que seja desconsiderado o movimento advindo dos processos instalados da globalização, porém, com vistas a superá-lo na sua forma tradicional de submissão, tal como tem ocorrido nos últimos tempos. A nova estrutura tecnológica deve ser aproveitada para o fortalecimento da educação e para formação no sentido da construção da cidadania, a começar pelos elementos constitutivos da avaliação e os instrumentos de participação social, como o Enade, por exemplo, que convoca todos os estudantes a darem sua percepção sobre os cursos de graduação e, assim, possibilita o acompanhamento da qualidade. 


\section{O EXAME NACIONAL DE DESEMPENHO DE ESTUDANTES (ENADE)}

O Exame Nacional de Desempenho dos Estudantes (Enade) é realizado pelo Instituto Nacional de Estudos e Pesquisas Educacionais Anísio Teixeira (Inep), órgão do Ministério da Educação (MEC) responsável pelas políticas de avaliação da educação básica e superior.

○ Enade aferirá o desempenho dos estudantes em relação aos conteúdos programáticos previstos nas diretrizes curriculares do respectivo curso de graduação, suas habilidades para ajustamento às exigências decorrentes da evolução do conhecimento e suas competências para compreender temas exteriores ao âmbito específico de sua profissão, ligados à realidade brasileira e mundial e a outras áreas do conhecimento. (BRASIL, 2004)

A partir dos resultados do Enade, os docentes, gestores e toda a comunidade acadêmica podem se utilizar, na promoção de ações de melhoria da qualidade dos cursos de graduação, dos dados extraídos por instituição de educação superior e disponibilizados pelas categorias administrativa, organização acadêmica, município, estado e região. A participação dos docentes nessa política nacional de avaliação, no que compete ao desenvolvimento do exame, tem início com a formação das Comissões Assessoras de Áreas, compostas por especialistas atuantes que prestam apoio técnico para a elaboração das diretrizes da prova a ser aplicada em cada área avaliada.

De 2004 até os dias atuais, mudanças significativas foram sendo implementadas com o intuito de avançar na universalização do Enade, de maneira que contemplasse maior participação dos estudantes e houvesse, consequentemente, maior fidedignidade dos seus resultados.

Inicialmente, pode-se falar da alteração, em 2009, da seleção em caráter amostral dos estudantes participantes para o modo censitário. Com a universalização da participação no exame, todos os estudantes ingressantes e concluintes inscritos pelas Instituições de Educação Superior são convocados para fazer a prova.

Essa decisão implicou um aumento significativo do número de participantes que anualmente realizam a prova. A inscrição 
6 item 10.3 do Anexo da Portaria Normativa $n$. 40, de 12 de dezembro de 2007, republicada em 29 de dezembro de 2010, institu o e-MEC, sistema eletrônico de fluxo de trabalho e gerenciamento de informações relativas aos processos de regulação, avaliação e supervisão da educação superior no sistema federa de educação e o cadastro e-MEC de instituições e cursos superiores, que consolida disposições sobre indicadores de qualidade - Banco de Avaliadores do

Sinaes (Basis) e o Exame Nacional de Desempenho de Estudantes (Enade). Alterou os percentuais de cálculo dos estudantes habilitados para o Enade e definiu novo conceito para os termos Ingressante $e$ Concluinte, a ser utilizado a partir de 2011: Ingressante - estudante que efetiva a matrícula inicial no curso.

Concluinte - estudante que tenha expectativa de concluir o curso no ano de referência, considerando o cumprimento de todos os requisitos para a integralização do curso em todos os componentes curriculares.

7 A Nota Técnica sobre cálculo do Conceito Enade está disponível em: <http://www.inep.gov.br/ download/enade/2009> dos estudantes pelas Instituições de Educação Superior, até o ano de 2010, teve como critérios: para os ingressantes, o cumprimento de 7 a $22 \%$ da carga horária mínima dos cursos de graduação (bacharelados e licenciaturas), ou entre 7 e $25 \%$ da carga horária dos cursos superiores de tecnologia; para os concluintes, o cumprimento de pelo menos $80 \%$ da carga horária mínima dos cursos de graduação, ou pelo menos 75\% da carga horária dos cursos tecnológicos, e que sejam prováveis concluintes no ano do exame.

Entretanto, a definição dos estudantes habilitados, por meio do cálculo desses percentuais, foi recentemente alterada por meio da Portaria n. 40/2007, republicada em 29 de dezembro de 2010. Passou-se a considerar, a partir de 2011, estudantes ingressantes todos aqueles que tiverem matrícula inicial no curso no ano do exame, e estudantes concluintes aqueles que tiverem matrícula no ano de conclusão do curso concomitante ao ano de realização do Enade daquela área. ${ }^{6}$ Estima-se que essa modificação proporcione melhoria da organização da gestão acadêmica na inscrição dos estudantes, por tornar mais fácil a identificação dos estudantes do ano inicial e do ano final que estarão habilitados para prova, sem a necessidade de análise do percentual cumprido no currículo do curso.

O Conceito Enade ${ }^{7}$ é calculado por área de avaliação e para cada curso de uma instituição de educação superior, situado em um mesmo município. Somam-se ao conceito Enade outros insumos e medidas que compõem a avaliação, além do conceito resultante do relatório das visitas in loco a cursos de graduação e instituições. Dentre esses insumos, está a titulação de docentes, o tempo dedicado para o desenvolvimento do projeto pedagógico, as produções acadêmicas, a infraestrutura, as metodologias e tecnologias educacionais, a qualidade de laboratórios, as bibliotecas e os demais espaços educacionais e de convivência na instituição. $O$ principal aspecto a ser considerado na aplicação do Enade, muito mais do que o resultado alcançado, é a participação do estudante no processo avaliativo, aspecto que deve se constituir como elemento central para saber a qualidade do curso que está sendo ofertado.

Acompanha o Enade o questionário do estudante, preenchido a partir de 2011 em caráter obrigatório, via on-line, nos últimos trinta dias que antecedem o exame. O estudante, logo após a realização da avaliação, responde ao questionário de 
percepção sobre a prova. O coordenador de curso também é solicitado a preencher um questionário sobre os aspectos da gestão do curso, no período de quinze dias após a aplicação do Enade. As informações extraídas desses questionários são de grande valor, uma vez que resultam em dados sobre as características e opiniões dos estudantes e dos coordenadores de cursos de graduação no Brasil.

Com relação à participação dos estudantes no Enade, há muito a ser feito para a conscientização da comunidade acadêmica acerca da importância da avaliação e do seu aspecto orientador na constituição do currículo dos cursos. Diante dessa percepção, o Enade precisa ser urgentemente repensado, a começar pela motivação do estudante para participação. Uma das mudanças nesse sentido é trazida pela recente alteração da legislação, que estabelece a possibilidade de substituição da participação dos estudantes ingressantes dos cursos da educação superior no Enade pela participação no Exame Nacional de Educação Básica (Enem). Ou seja, os estudantes que participaram do Enem não precisarão realizar o Enade quando estiverem no primeiro ano do curso de graduação. O novo texto está contemplado no Artigo 33-F da Portaria Normativa n. 40, de 12 de dezembro de 2007, republicada em 29 de dezembro de 2010:

Art. 33-F O Enade será aplicado aos estudantes ingressantes e concluintes de cada curso a ser avaliado, conforme lançados no Cadastro e-MEC, observados os respectivos códigos e os locais de oferta informados.

§ 1으 Enade será composto de uma prova geral de conhecimentos e uma prova específica de cada área, voltada a aferir as competências, habilidades e conteúdos agregados durante a formação.

$\S 2^{\circ}$ Os alunos ingressantes participarão apenas da prova geral, que será elaborada com base na matriz de referência do Exame Nacional do Ensino Médio (Enem).

\& 3응 alunos ingressantes que tiverem realizado o Enem, aplicado com metodologia que permita comparação de resultados entre edições do exame, poderão ser dispensados de realizar a prova geral do Enade, mediante apresentação do resultado válido.

$\S 4^{\circ}$ Os alunos concluintes realizarão a prova geral de conhecimentos e a prova específica da área. 
As mudanças dividem opiniões entre os membros da comunidade acadêmica. Para alguns, a decisão é positiva, pois representa uma solicitação antiga das instituições, dos docentes e estudantes, que consideravam que realizar o Enade ao fim do primeiro ano da graduação, quando o estudante já adquirira conhecimentos, não expressava a condição de ingressante daquele curso de graduação. Como esse resultado mede o conhecimento adquirido pelo aluno durante a graduação e é considerado no cálculo de conceitos, como o indicador de diferença entre o desempenho observado e esperado (IDD), o Enem, realizado ao final do ensino médio, traria maior equidade por se realizar antes do início do curso.

Afirma-se, também, que a nova metodologia poderá trazer maior otimização do processo de avaliação dos estudantes ingressantes, além de ser mais precisa para as ações realizadas pelas instituições, que no primeiro ano do curso se ocupam de ampliar a formação obtida pelos estudantes no ensino médio e enriquecer sua formação geral e específica, voltada ao curso escolhido.

\section{PARTICIPAÇÃO DA COMUNIDADE ACADÊMICA NAS POLÍTICAS DE AVALIAÇÃO DA EDUCAÇÃO SUPERIOR}

No intuito de resguardar os resultados do exame para o conjunto do processo avaliativo, faz-se necessário um amplo movimento que mobilize as instâncias governamentais, os docentes e os discentes em campanhas não só para a participação dos estudantes no Enade, como também para a responsabilidade com a consolidação da cultura da avaliação no interior das instituições de educação superior.

As instituições vêm fortalecendo os colegiados e demais setores com informações e com a formação de equipes responsáveis pela sensibilização da comunidade acadêmica para a importância desse processo avaliativo, em especial do Enade. Por sua vez, o Inep tem buscado alternativas para ampliar a participação dos docentes, incluindo a realização de seminários nacionais para os coordenadores de curso e procuradores institucionais (PIs), com vistas à divulgação do Exame e ao fortalecimento da comunicação institucional. A participação 
dos docentes é implicada nesse processo, com a implantação de uma nova metodologia de organização das provas que contemple Editais de Chamada Pública de Docentes para a elaboração de questões para o Banco Nacional de Itens da Educação Superior (BNI).

O processo passou a ser coordenado diretamente pelo Inep, a partir de um banco de questões elaboradas por professores vinculados às Instituições de Educação Superior. O BNI da educação superior é concebido, portanto, como um acervo de questões elaboradas a partir de matrizes de conteúdos, competências e habilidades pré-definidos pelas Comissões Assessoras de Área, que permitem a montagem de provas para estimar com a maior precisão possível a proficiência dos estudantes com relação aos conteúdos de seus cursos de graduação.

Para o processo de elaboração do exame foi registrada a inscrição de 7.642 docentes de instituições públicas e privadas de todos os estados brasileiros e do Distrito Federal. Desse total, 4.325 docentes se inscreveram para elaborar questões de formação geral e 510 registraram-se como revisores de língua portuguesa. Para as áreas e cursos superiores de tecnologia (CST), avaliados pelo Enade 2010, o total de inscritos foi de 2.807 docentes, dentre os quais 1.838 se inscreveram como elaboradores e 969 , como revisores. A partir dessa inscrição, foram convocados 400 docentes para elaboração das questões de prova, distribuídos entre 320 elaboradores e 80 revisores técnico-pedagógicos.

O principal aspecto a ser destacado nesse processo é a abertura para a participação cada vez mais efetiva da comunidade acadêmica nos processos de construção dos instrumentos de avaliação da educação superior brasileira. No caso das provas do Enade, convocar professores por uma chamada pública é a garantia de que o Estado está promovendo a pluralidade no processo avaliativo e consolidando o diálogo entre o avaliador e o avaliado.

\section{OS INDICADORES DE QUALIDADE DA EDUCAÇÃO SUPERIOR}

$O$ aspecto formativo da avaliação pressupõe que seus resultados sirvam de referencial para o aprimoramento da gestão das instituições e que sejam disponibilizadas as informações 
8 São indicadores de qualidade calculados pelo Inep, com base nos resultados do Enade e demais insumo constantes das bases de dados do MEC e segundo metodologia própria aprovada pela Comissão Naciona

de Avaliação da Educação Superior (Conaes)

atendidos os parâmetros da

Lei n. 10.861, de 2004

- - de cursos superiores:

o Conceito Preliminar de Curso (CPC), instituído pela

Portaria Normativa no 4, de 05 de agosto de 2008;

II - de instituições de educação superior: o Índice Geral de Cursos (IGC) avaliados da instituição, instituído pela Portaria Normativa no 12, de 05 de setembro de 2008

III - de desempenho de estudantes: o conceito obtido

a partir dos resultados do Enade (Art. 33-B da Portaria n. 40/2007, republicada em 29 de dezembro de 2010)

$9 \bigcirc$ CPC será calculado no ano seguinte ao da realização do Enade de cada área, observado o art. 33-E,

com base na avaliação de desempenho de estudantes corpo docente, infraestrutura, recursos didático pedagógicos e demais insumos, conforme orientação técnica aprovada pela Conaes.

( $\$ 1$ do Art. 33-B da Portaria

n. 40/2007, republicada em

29 de dezembro de 2010) É

calculado a partir de variáveis

extraídas do Enade, do

questionário do estudante e do cadastro docente. Para o cálculo, os insumos são assim distribuídos:

a) corpo docente do curso $(0,3)$ b) porcentagem de professores

no mínimo mestre $(0,05)$ c) porcentagem de professores

no mínimo doutor $(0,20)$ d) porcentagem de professores não horistas $(0,05)$; e) informações do Módulo de Docentes do Censo da Educação Superior mais recente;

f) percepção dos alunos com relação à infraestrutura e organização didádico - pedagógica do curso coletadas do questionário do estudante do Enade $(0,1)$ suficientes às tomadas de decisões e ao replanejamento das ações e investimentos, com base na avaliação interna e externa realizada periodicamente.

Nesta perspectiva, a avaliação de estudantes cada vez mais se apresenta como elemento indutor de qualidade dos cursos. Conforme Verhine (2006), a premissa é que os exames devem oferecer contribuições para o aprimoramento e delineamento do próprio exame atual, para efeitos diagnósticos, de regulação ou de quaisquer outras intenções do Estado na sua função avaliativa.

\begin{abstract}
O grande impacto do Enade está relacionado não a mudanças técnicas, mas principalmente, aos aspectos regulatórios do exame, que deixam de existir isoladamente. Nesse sentido, é imprescindível que sejam criados e divulgados os critérios de utilização das notas do Enade na composição dos conceitos da Avaliação de Cursos e da Avaliação de Instituições. (VERHINE, 2006)
\end{abstract}

A qualidade da educação superior também pode ser expressa nos relatórios resultantes da participação do estudante no Enade, pois eles contêm um conjunto de informações sobre os cursos e podem ser objeto de reflexão para a coordenação dos cursos, junto com os docentes e demais órgãos colegiados. Destaca-se que as informações resultantes do processo de avaliação subsidiam a tomada de decisão dos gestores sobre mudanças necessárias no curso, como a revisão de currículos, de projetos e de programas que venham a incidir em novas práticas e em tecnologias educacionais aplicadas à necessária formação do estudante.

No âmbito do Ministério da Educação, esses resultados vêm sendo utilizados para ações complementares ao atual processo de avaliação da educação superior. Exemplo disso são os resultados do Enade e as informações do Censo da Educação Superior utilizados como base nos cálculos dos indicadores de qualidade. ${ }^{8}$

O Conceito Preliminar de Curso (CPC) $)^{9}$ é um desses indicadores e foi criado com a intenção de avaliar e melhorar a qualidade da educação. O valor obtido no CPC (Tabela 2) é agrupado por faixas e definido em valores de $1(\mathrm{um})$ a 5 (cinco). 
TABELA 2 - Ciclos de aferição do Spaece - 2007 a 2010 na determinação dos indicadores

\begin{tabular}{c|c:c:c}
\hline VALOR DO CPC & $\begin{array}{c}\text { QUANTIDADE } \\
\text { DE CURSOS }\end{array}$ & $\begin{array}{c}\text { REPRESENTATIVIDADE } \\
\text { (DO TOTAL DE CURSOS) }\end{array}$ & $\begin{array}{c}\text { REPRESENTATIVIDADE } \\
\text { (DS CURSOS COM CPC) }\end{array}$ \\
\hline 1 & 47 & $0,69 \%$ & $0,94 \%$ \\
2 & 1649 & $24,24 \%$ & $33,03 \%$ \\
3 & 2570 & $37,55 \%$ & $51,47 \%$ \\
4 & 661 & $9,71 \%$ & $13,24 \%$ \\
5 & 66 & $0,97 \%$ & $1,32 \%$ \\
Sem conceito & 1811 & $26,62 \%$ & - \\
Total & 6804 & $100,0 \%$ & - \\
\hline
\end{tabular}

Fonte: Resultados dos Indicadores de Qualidade da Educação Superior, 2009, MEC/Inep/Dired (BRASIL, 2009).

O CPC somente pode ser calculado para os cursos que estão em fase de renovação de reconhecimento e que, portanto, participaram do Enade nas áreas avaliadas em cada triênio. Considerando o pouco tempo de vigência do CPC, em uma análise inicial dos resultados das áreas avaliadas pelo Enade 2009, podemos inferir que o grande número de cursos sem CPC ocorre devido à expansão da educação superior, já que a falta de conceito Enade, seja de ingressantes ou de concluintes, ${ }^{10}$ ou mesmo desses insumos para o cálculo do IDD, inviabiliza o cálculo do CPC para 1.811 cursos desse ciclo.

A intenção na utilização desses indicadores é a de acompanhar a qualidade, entretanto, para evitar a competição entre as Instituições, é preciso que seja justa e coerente com a proposta da avaliação. E considerando a característica dinâmica e flexível que todo o processo avaliativo enseja, muitos ajustes ainda devem ser feitos e são indispensáveis.

\section{CONSIDERAÇÕES FINAIS}

Na discussão sobre o Enade como elemento indutor da qualidade da educação superior, busca-se verificar as contribuições que o exame pode expressar no efetivo aprimoramento do curso e da formação dos estudantes de graduação.

A análise da metodologia da avaliação de desempenho dos estudantes demonstra que foram sendo incluídas, no decorrer da sua implementação, novas práticas no processo avaliativo.
10 O conceito Enade

ingressante é calculado para cursos que tenham no mínimo dois ingressantes, e o conceito Enade concluinte é calculado para cursos que tenham no mínimo dois concluintes. 
$11 \bigcirc$ Sinaes, ao promover a avaliação de instituições, de cursos e de desempenho dos estudantes, deverá assegurar - avaliação institucional, interna e externa, contemplando a análise global e integrada das dimensões, estruturas, relações, compromisso social, atividades, finalidades

e responsabilidades sociais das instituições de educação superior e de seus cursos; II - o caráter público de todos os procedimentos, dados e resultados dos processos avaliativos; III - o respeito à identidade e à diversidade de instituições e de cursos; IV - a participação do corpo discente, docente e técnico-administrativo das instituições de educação superior, e da sociedade civil, por meio de suas representações (Art. 20 da Lei n. 10.861/2004).
Exemplo disso são as alterações na prova, primeiro somente para concluintes, depois para ingressantes e concluintes: a substituição do caráter de amostragem pela forma censitária de seleção; a instalação do ciclo avaliativo com a aplicação trienal do exame, distribuído por áreas de cursos; a criação dos indicadores de qualidade da avaliação e o peso atribuído aos resultados do exame no respectivo cálculo; o cômputo apenas do resultado dos concluintes no Conceito Enade; a recente proposta de utilização do Enem como exame de referência para os ingressantes, em substituição ao Enade, entre outras alterações características de um processo de avaliação, que é por natureza, dinâmico.

Enquanto instrumento de avaliação da formação dos estudantes, o Enade busca se constituir como um diagnóstico e oferecer informações que, juntamente com a avaliação dos cursos e das instituições e somadas aos indicadores de qualidade, possibilitem às instituições a promoção de novas ações que venham a melhorar os aspectos identificados como fragilidades na gestão acadêmica e na organização pedagógica dos cursos.

De uma forma geral, o que se observa é que tanto as informações de relatórios quanto os dados e características da avaliação não são conhecidos pelos cursos, e pouco ou nada contribuem se não forem motivo de reflexão e análise para possíveis melhorias, além de ocasionar uma desvalorização da importância da realização do exame para a instituição e para os seus estudantes. É importante resgatar os princípios da constituição do Sinaes ${ }^{11}$ de forma a assegurar que a avaliação tenha sentido e significado para quem avalia e para quem é avaliado. Certamente, os ganhos nesse processo serão atribuídos à sociedade.

\section{REFERÊNCIAS}

AMARAL, Alberto. Avaliação e qualidade do ensino superior. As Muitas racionalidades da qualidade. In: LEITE, Denise (Org.). Avaliação participativa e qualidade: os atores locais em foco. Tradução de Mircele Dornelles. Porto Alegre: Sulina; Editora Universitária Metodista IPA, 2009. p. 11-32.

BRASIL. Ministério da Educação. Instituto Nacional de Estudos e Pesquisas Educacionais Anísio Teixeira. Censo da educação superior: 2009: Resumo técnico. Brasília, 2011. Disponível em: <http://download.inep.gov.br/download/superior/ censo/2009/resumo_tecnico2009.pdf>. Acesso em: 15 maio 2011.

Lei n. 9.131, de 24 de novembro de 1995. Altera dispositivos da Lei 
n. 4.024, de 20 de dezembro de 1961 e dá outras providências. Diário Oficial [da] República Federativa do Brasil, Brasília, DF, 24 nov. 1995. Edição Extra, p. 19257. Disponível em: <http://www.planalto.gov.br/ccivil_03/Leis/L9131. htm>. Acesso em: 1 fev. 2011.

Lei n. 10.172, de 9 de janeiro de 2001. Aprova o Plano Nacional de Educação e dá outras providências. Brasília, DF.

Lei n. 10.861, de 14 de abril de 2004. Institui o Sistema Nacional de Avaliação da Educação Superior (Sinaes). Diário Oficial [da] República Federativa do Brasil, Brasília - DF, 15 de abril de 2004, n. 72, Seção 1, p. 3-4.

Portaria Normativa n. 40, de 12 de dezembro de $2007\left(^{*}\right)$, Republicada por ter saído, no DOU n. 239, de 13-12-2007, Seção 1, p. 39-43, com incorreção no original. Diário Oficial [da] República Federativa do Brasil, Brasília - DF, n. 249, seção 1, quarta-feira, 29 de dezembro de 2010, páginas 23-31. Disponível em: < http://www.in.gov.br/autenticidade.html>. Acesso em: 1 fev. 2011, pelo código 00012010122900023.

Resultados do conceito preliminar de cursos avaliados no Enade 2009. Planilhas para Download. Disponível em: <http://portal.inep.gov.br/ notas-tecnicas>. Acesso em: 15 maio 2011.

DIAS SOBRINHO, José. Educação superior, globalização e democratização: o debate ético-político. In: LEITE, Denise (Org.). Avaliação Participativa e qualidade: os atores locais em foco. Porto Alegre: Sulina; Editora Universitária Metodista IPA, 2009. p. 33-55.

SCHWARTZMAN, Simon. Ciência, universidade e ideologia: a política do conhecimento. Centro Edelstein de Pesquisas Sociais, 2008. Disponível em: <www.bvce.org>. Acesso em: 20 maio 2011.

SGUISSARDI, Valdemar. Universidade brasileira no século XXI: desafios do presente. São Paulo: Cortez, 2009. p. 109-139.

VERHINE, Robert Evan; DANTAS, Lys Maria Vinhaes; SOARES, José Francisco. Do Provão ao Enade: uma análise comparativa dos exames nacionais utilizados no ensino superior brasileiro. Ensaio: Aval. Pol. Públ. Educ., Rio de Janeiro, v. 14, n. 52, p. 291-310, jul./set. 2006.

\section{CLAUDIA MAFFINI GRIBOSKI}

Professora da Universidade de Brasília (UnB). Doutoranda do Programa de Pós-Graduação em Educação da UnB. Vice-coordenadora do Grupo de Pesquisa e Estudos sobre Avaliação da Educação Superior (Gepaes/UnB). Diretora de Avaliação da Educação Superior do Instituto Nacional de Estudos e Pesquisas Educacionais Anísio Teixeira (Inep) claudiagriboski@unb.br/claudia.griboski@inep.gov.br 